\title{
Otimização da geração de solução oxidante através da eletrólise de rejeito de dessalinizadores utilizando planejamento fatorial
}

\author{
Optimization of the generation of oxidizing solution through dessalinizer waste electrolysis using \\ experimental design
}

Optimización de la generación de solución oxidante mediante electrolisis de residuos desalinizadores mediante diseño experimental

\section{Resumo}

Neste trabalho foram realizados estudos para a produção de solução oxidante a partir de rejeito de dessalinizadores de água do mar pelo processo de eletrólise. O experimento foi realizado em escala de bancada. A solução oxidante foi gerada eletroliticamente, a partir de rejeitos de dessalinizadores de água com concentrações de $3,8 \times 10^{4} \mathrm{mg} \mathrm{de} \mathrm{Cl}^{-} \mathrm{L}^{-1}$. $\mathrm{O}$ processo de eletrólise tinha duração de sessenta minutos, ao final foram medidos o $\mathrm{pH}$, temperatura e cloro residual. O experimento investigou as características de produção de hipoclorito de sódio para fins de desinfecção, foram investigados: tipos de eletrodos, distância entre eletrodos e concentração da amostra. O planejamento fatorial indicou que a geração de solução oxidante será favorecida quando utilizado o anodo de titânio e catodo de titânio ou aço, solução do rejeito diluída e distância de eletrodo de $20 \mathrm{~mm}$. Teor máximo de cloro da solução oxidante gerada foi de $0,8 \mathrm{mgL}^{-1}$, nas condições avaliadas. Como continuidade dos experimentos serão avaliadas a cinética de reação para obtenção de maior concentração de solução oxidante, nas condições ótimas do experimento, bem como, serão caracterizados os resíduos gerados para estudo de viabilidade e aplicação no saneamento.

Palavras-chave: Dessalinização; Rejeito; Eletrorremediação; Osmose reserva; Oxidante; Planejamento fatorial.

\begin{abstract}
This work carried out studies about the use of the electrolysis process to produce oxidant solutions from water desalinators wastes for water disinfection. The experiment was conducted in laboratory scale. The oxidant solution were generated by electrolysis from wastes of water desalinators that presented concentrations of $3,8 \times 10^{4} \mathrm{mg} \mathrm{Cl}-\mathrm{L}^{-1}$. The electrolysis process lasted sixty minutes, at the end of which the $\mathrm{pH}$, temperature and residual chlorine. The experiment investigated the characteristics of sodium hypochlorite production for disinfection purposes, four main factors were investigated: electrode types, distance between electrodes and sample concentration. Factorial design indicated that the generation of oxidizing solution will be favored when using the titanium anode and titanium or steel cathode, diluted tailings solution and electrode distance of $20 \mathrm{~mm}$. It was observed that the maximum chlorine content of the generated oxidizing solution was $0.8 \mathrm{mgL}^{-1}$, under the conditions evaluated. As a continuation of the experiments, the reaction kinetics to obtain a higher concentration of oxidizing solution will be evaluated, under the optimal conditions of the experiment, as well as the waste generated for feasibility study and application in the sanitation.
\end{abstract}

Keywords: Desalination; Residue; Electroremediation; Reverse osmosis; Oxidant; Experimental design.

\section{Resumen}

En este trabajo se realizaron estudios sobre el uso del proceso de electrólisis para producir soluciones oxidantes a partir de residuos de desaladoras de agua para la desinfección del agua. El experimento se realizó a escala de laboratorio. La solución oxidante se generó por electrólisis a partir de desechos de desaladores de agua que presentaron concentraciones de En este trabajo de $3,8 \times 10^{4} \mathrm{mg} \mathrm{Cl}^{-} \mathrm{L}^{-1}$. El proceso de electrólisis duró sesenta minutos, al final de los cuales el $\mathrm{pH}$, la temperatura y el cloro residual. El experimento investigó las características de la producción de hipoclorito de sodio con fines de desinfección, se investigaron cuatro factores principales: tipos de electrodos, distancia entre electrodos y concentración de la muestra, el diseño factorial indicó que la generación de 
solución oxidante se verá favorecida al utilizar el ánodo de titanio y titanio o acero cátodo, solución de relaves diluidos y distancia entre electrodos de $20 \mathrm{~mm}$. Se observó que el contenido máximo de cloro de la solución oxidante generada fue de $0,8 \mathrm{mgL}^{-1}$, en las condiciones evaluadas. Como continuación de los experimentos, se evaluará la cinética de reacción para obtener una mayor concentración de solución oxidante, en las condiciones óptimas del experimento, así como los residuos generados para el estudio de factibilidad y aplicación en el saneamiento.

Palabras clave: Desalación; Residuo; Electrorremediación; Osmosis inversa; Oxidante; Diseño experimental.

\section{Introdução}

A escassez de água tornou-se um dos maiores desafios do ser humano na atualidade. A dessalinização tornou-se amplamente usada para fornecer água limpa e segura em muitos países. Os resíduos gerados pelos dessalinizadores, provém, essencialmente, da água não permeada pelas membranas e pelo processo de retrolavagem. Os efluentes gerados (rejeito) pelo processo de dessalinização ameaçam o meio ambiente da região, pois são águas com elevados teores de sais, e cujo método atual de disposição, geralmente, é o uso de um corpo receptor ou simplesmente o despejo indiscriminado no solo, contribuindo para contaminar mananciais, solo e até a fauna e flora (Amorim et al., 2000). A depender do equipamento de dessalinização usado e da qualidade da água do poço, a quantidade de rejeito gerado é da ordem de 30 a $70 \%$ do total de água que passa pelo equipamento (Porto et al., 1999). Apesar do significante impacto ambiental causado pela instalação de dessalinizadores, as águas salobras podem e devem ser aproveitadas, como alternativa de suprimento de água potável, nas regiões de escassez (Amorim et al., 2000).

O rejeito de usinas de dessalinização tem uma alta salinidade e inclui substâncias e produtos químicos usados na lavagem das membranas que contêm sais, utilizados na remoção de incrustações. O descarte do concentrado rejeitado é considerado a principal preocupação econômica e ambiental, especialmente em regiões que dependem de dessalinização para obtenção de água potável (El-Naas, 2011).

$\mathrm{O}$ concentrado de unidades de dessalinização próximas à costa do mar, normalmente é lançado ao mar. O tipo de dispersão e a diluição natural da salmoura depende de vários fatores, como a localização do tubo de descarga, as ondas, marés, profundidade da água, correntes marítimas e batimetria, são fatores que podem explicar a forma da mistura da salmoura com o mar no ponto de disposição do emissário (Mickley, 2000). Entretanto, o maior problema se encontra em unidades de dessalinização de águas salobras instaladas no interior do continente, onde o concentrado chega a possuir uma concentração até 10 vezes a da água bruta original (Riffel, 2005).

Alguns métodos conhecidos de remediação do concentrado do dessalinizador consistem na redução do volume de efluentes e sua transformação em um produto sólido, através da evaporação solar, com aproveitamento dos sais cristalizados pelo setor humano e animal (Amorim et al, 2000). Neste método, a salmoura é bombeada para lagoas e evaporada à secura para disposição final. Estas lagoas de evaporação são geralmente mais eficazes em climas áridos e semiáridos, que têm taxas de evaporação constantes e relativamente rápidas, uma vez que dependem da energia solar para evaporar a água de salmoura. Ahmed et al. (2000) estudaram literatura relacionada às lagoas de evaporação e sugeriram o melhor design para as lagoas. Porto et al. (2000, 2001, 2020) cultivaram durante um ano, nos campos da EMBRAPA (Empresa Brasileira de Agropecuária) a Atriplex numulária, uma planta halófita, que foi irrigada com rejeito proveniente do processo de dessalinização. Mota et al. (2005) e Matos et al. (2006) utilizaram o concentrado na geração de solução oxidante para desinfecção, utilizando um eletrolisador, que produzia em 8 horas, 25 litros da solução oxidante por batelada. Outras pesquisas envolvem a criação de crustáceos, tilápias, capazes de se desenvolverem em um meio salino (Montenegro et al., 2001). Apesar de existirem vários métodos para tratamento e disposição dos resíduos gerados pelos dessalinizadores, é extremamente importante encontrar métodos alternativos, visando a proteção do meio ambiente e menores custos envolvidos nos processos e operações. O descarte ou gerenciamento de salmoura é um grande desafio ambiental para a maioria das comunidades.

Esta pesquisa investigou um método de tratamento do rejeito ou concentrado do dessalinizador para produção de 
solução oxidante em escala laboratorial, objetivando assim, conferir um melhor aproveitamento para o concentrado e reduzir a quantidade de rejeito descartada no mar.

\section{Metodologia}

Neste trabalho foi desenvolvido pesquisa experimental em laboratório, para determinar a melhor configuração da célula eletrolítica para geração de solução oxidante utilizando a técnica de planejamento fatorial sugerida por Peralta-Zamora et al. (2005), que possibilita identificar os fatores e/ou interações de fatores mais relevantes para a resposta do experimento na geração de cloro.

As principais características dos equipamentos e materiais utilizados nos experimentos deste estudo, serão apresentadas a seguir:

\subsection{Célula eletrolítica}

Para os estudos de eletrorremediação serão utilizadas uma célula eletroquímica de construção própria, em vidro, cilíndrica, com capacidade de $600 \mathrm{~m}^{3}$ de volume livre. Os ensaios de eletrólise foram executados com uma fonte, com capacidade de produção de solução oxidante por batelada. Nos ensaios de eletrorremediação, será utilizada uma célula eletroquímica (Figura 1). Os eletrodos terão como ânodo e como cátodo o titânio e/ou aço, o tipo de eletrodo foi estudado conforme o planejamento fatorial. E por fim, liga-se a célula à fonte de energia através de pinças "crocodilo" presas aos elétrodos.

Figura 1: Desenho esquemático do arranjo experimental.

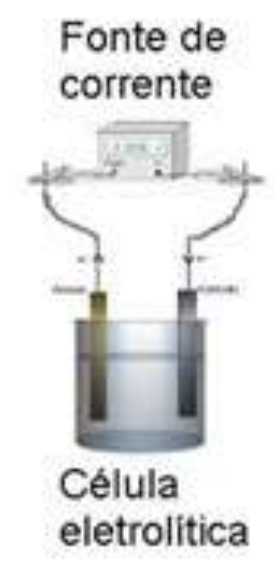

Fonte: Autores (2021).

A fonte de energia elétrica será promovida com gerador de corrente contínua, para o desenvolvimento dos experimentos foi utilizada uma fonte, modelo PS-305D YANXUN. O equipamento possui uma fonte de corrente com alimentação de $220 \mathrm{~V} / 2 \mathrm{~A}$ e saída de $30 \mathrm{~V} / 5 \mathrm{~A}$. A célula eletrolítica constituída por um par de eletrodos, formado por duas placas paralelas, com espessuras de $0,6 \mathrm{~mm}$ e áreas de 7,5 $\mathrm{cm}^{2}$. As placas dos eletrodos foram ligadas aos cabos de alimentação, um vermelho conectado ao eletrodo positivo, e o cabo preto, ao eletrodo negativo. Foi utilizado um volume do rejeito de $250 \mathrm{~cm}^{3}$, para cada batelada, na câmara eletrolítica e, logo a seguir, a fonte de corrente foi ligada à rede elétrica, dando início ao processo de eletrólise onde ocorre a reação de transformação do rejeito em solução oxidante. 


\subsection{Análises químicas}

Nesta pesquisa serão utilizadas amostras de rejeito oriundo do processo de dessalinização do Arquipélago de Fernando de Noronha, Pernambuco, provenientes do tratamento de água do mar, coletadas no primeiro semestre de 2021, estocadas a $4^{\circ} \mathrm{C}$ até o uso.

O dessalinizador localizado na Estação de Tratamento de Água - ETA Boldró, tem uma capacidade de produção atual de $48 \mathrm{~m}^{3} / \mathrm{h}$, produzindo em média $15 \mathrm{~m}^{3} / \mathrm{h}$ de rejeito. O dessalinizador opera $24 \mathrm{~h} /$ dia. Sendo atualmente todo o rejeito produzido devolvido para o mar.

Foram utilizados cerca de 10 litros do rejeito, duas amostras de 5 litros, armazenados em recipientes plásticos até a realização dos ensaios de eletrólise. Os ensaios foram realizados em Recife/PE, no Laboratório de Ensaios de Tratabilidade da COMPESA (Companhia Pernambucana de Saneamento). Foram realizados ensaios experimentais de bancada, em duplicata de acordo com o planejamento fatorial. As amostras foram caracterizadas para parâmetros físico-químicos e metais. O rejeito do dessalinizador foi analisado quanto aos parâmetros: $\mathrm{pH}$, turbidez, cor aparente, condutividade elétrica, alcalinidade total, dureza total, cálcio, magnésio, cloreto, sulfato, nitrato e metais, de acordo com a metodologia recomendada por Eaton et al. (2017). Foram adotados como referência padrões estabelecidos nas Resoluções CONAMA 430/11 para efluentes e CONAMA 357/05 para classes de água (Brasil, 2005, 2011).

Para determinar o cloro residual, empregou-se o método reflectométrico por meio de um colorímetro portátil DR 300 $\mathrm{HACH}$, utilizando cubeta com percurso ótico de $1,0 \mathrm{~cm}$ e reagente DPD (N,N-dietil-P-Fenilenodiamino). A escolha desse método justifica-se pelo fato do equipamento apresentar alta sensibilidade, obtendo-se valor de cloro em baixas concentrações

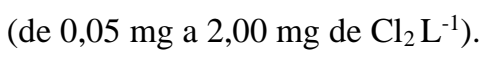

Para determinação do pH foi utilizada sonda HQ 40 d Multi HACH e a temperatura foi aferida com um Termômetro ASTM Incoterm. O tempo total da reação de eletrólise foi de 60 minutos. Ao final da reação foi determinado o cloro residual, pH e temperatura e demais parâmetros físico químicos.

\subsection{Planejamento Fatorial}

Para alcançar os objetivos propostos neste trabalho foi realizado um experimento estatisticamente planejado, do tipo fatorial completo em dois níveis $\left(2^{\mathrm{k}}\right)$, em que $\mathrm{k}$ é o número de parâmetros ou variáveis de entrada estudadas. Sendo as variáveis selecionadas para o processo: Eletrodos de titânio e aço, distância entre eletrodos e diluição do rejeito. Considerando um tempo de reação de 60 minutos. Portanto, o planejamento fatorial completo resultaria em uma configuração 24. Todas as análises, cálculos estatísticos e gráficos foram obtidos por meio do software STATISTICA ${ }^{\circledR}$. A Tabela 1 apresenta os níveis das variáveis estudadas. Os experimentos foram realizados de forma aleatória como forma de minimizar os efeitos de erros devido à repetição dos experimentos (Barros Neto et al., 2010; Rodrigues, 2005). 
Tabela 1: Variáveis e níveis estudados no planejamento fatorial $2^{4}$

\begin{tabular}{llrc}
\hline Variáveis & Fatores & & Níveis \\
& & Inferior (-) & Superior (+) \\
\hline Anodo & Material do eletrodo & Aço & Titânio \\
Catodo & Material do eletrodo & Titânio & 1 \\
Diluição & Fator de diluição do rejeito & 10 & 250 \\
Distância & Distância entre eletrodos (mm) & 20 \\
\hline
\end{tabular}

Fonte: Autores (2021).

A escolha dos níveis dos fatores foi feita com base na revisão de artigos e na literatura aplicável a geração de cloro. Foram realizados 16 ensaios em duplicata, totalizaram 32 ensaios, tempo de experimento de 60 minutos. A estimativa do erro pode ser obtida pela réplica.

\section{Resultados e Discussão}

\subsection{Célula eletrolítica}

Na célula eletroquímica foram utilizados elétrodos de aço inox inoxidável e titânio, combinados de acordo com os ensaios planejados na Tabela 1. O experimento foi conduzido mantendo a fonte ajustada em $30 \mathrm{~V}$. A montagem do experimento, ilustrada na Figura 2, seguiu as diretrizes estabelecidas em trabalhos de investigação de âmbito similares já existentes na literatura, ao final do tempo de experimento foram realizadas análises de caracterização da amostra.

Figura 2: Montagem experimento.

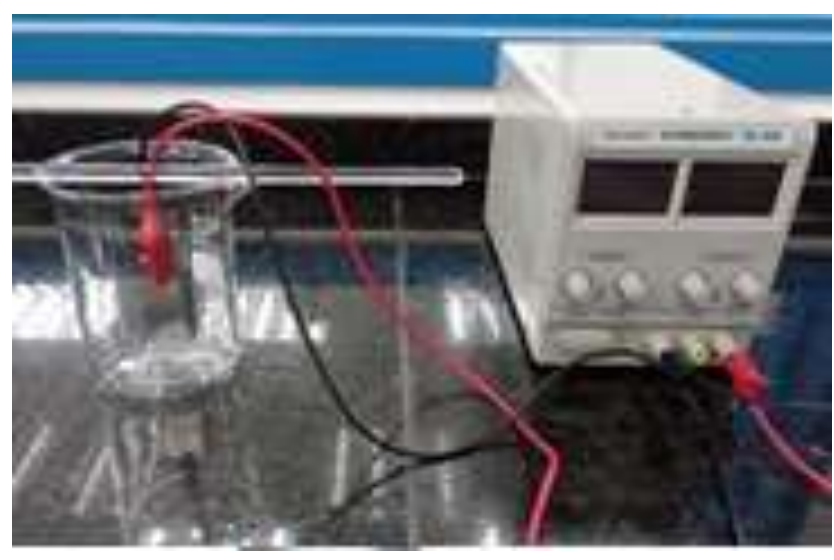

Fonte: Autores (2021).

\subsection{Análises químicas}

Foi feita a caracterização do rejeito 1 e 2, oriundos do processo de dessalinização da água do mar de duas amostras. O resultado está apresentado na Tabela 2. 
Tabela 2: Caracterização do rejeito do dessalinizador da água do mar da ETA Boldró (Fernando de Noronha/PE) e estudos comparativos.

\begin{tabular}{|c|c|c|c|c|c|c|c|}
\hline Parâmetros & $\begin{array}{l}\text { Rejeito } 1 \\
\text { ETA } \\
\text { Boldró }\end{array}$ & $\begin{array}{l}\text { Rejeito } 2 \\
\text { ETA } \\
\text { Boldró }\end{array}$ & $\begin{array}{l}\text { Rejeito } \\
\text { Rabah, } \\
(2017)\end{array}$ & $\begin{array}{l}\text { Rejeito } \\
\text { Silva } \\
(2019)\end{array}$ & $\begin{array}{l}\text { Rejeito } 1 \\
\text { Mota et } \\
\text { al. (2005) }\end{array}$ & $\begin{array}{l}\text { Rejeito } 2 \\
\text { Mota et al. } \\
(2005)\end{array}$ & $\begin{array}{l}\text { Rejeito 3 } \\
\text { Mota et } \\
\text { al.(2005) }\end{array}$ \\
\hline $\mathrm{pH}$ a $25^{\circ} \mathrm{C}$ & 8,0 & 7,9 & 7,5 & 8,54 & 6,8 & 7,2 & 7,7 \\
\hline Turbidez (uT) & 0,2 & 0,2 & & 2,7 & 0,6 & 0,9 & 0,7 \\
\hline Cor aparente $(\mathrm{uH})$ & $<0,1$ & 2 & & 0 & 6 & 5 & 12 \\
\hline $\begin{array}{l}\text { Condutividade elétrica } \\
\left(\mu \mathrm{Scm}^{-1}\right)\end{array}$ & 57.900 & 65.800 & 95.000 & 116.500 & 3.800 & 5.400 & 24.500 \\
\hline $\begin{array}{l}\text { Alcalinidade total (mg } \\
\mathrm{CaCO}_{3} \mathrm{~L}^{-1} \text { ) }\end{array}$ & 221,1 & 227,1 & 216 & & 240,6 & 245,5 & 55,7 \\
\hline Dureza total $\left(\mathrm{mg} \mathrm{CaCO}_{3} \mathrm{~L}^{-1}\right)$ & 13.308 & 12.911 & 19.800 & 11.300 & 1.325 & 1.386 & 10.977 \\
\hline Cálcio (mg Ca L-1 $)$ & 837 & 838 & 700 & & 160 & 165 & 1.407 \\
\hline Magnésio (mg Mg L-1 $)$ & 2.725 & 2.628 & 2.926 & & 224 & 236 & 1.812 \\
\hline Cloreto (mg Cl- $\mathrm{L}^{-1}$ ) & 38.308 & 40.598 & 37.562 & 33.376 & 480 & 488 & 10.200 \\
\hline Sulfato $\left(\mathrm{mg} \mathrm{SO}_{4} \mathrm{~L}^{-1}\right)$ & 5.359 & 5.427 & 5.850 & & 41 & 38 & 71 \\
\hline Nitrato $\left(m g ~ N-N_{3} L^{-1}\right)$ & $<0,001$ & 9,6 & 5,4 & & 0,1 & $<0,1$ & 2,0 \\
\hline $\mathrm{Al}\left(\mathrm{mg} \mathrm{L}^{-1}\right)$ & 0,620 & 0,350 & & & & & \\
\hline$B\left(\mathrm{mg} \mathrm{L}^{-1}\right)$ & 4,346 & 5,638 & 7,1 & & & & \\
\hline $\mathrm{Ba}\left(\mathrm{mg} \mathrm{L}^{-1}\right)$ & $<0,02$ & $<0,02$ & & & & & \\
\hline $\mathrm{Cu}\left(\mathrm{mg} \mathrm{L}^{-1}\right)$ & $<0,005$ & 0,010 & & & & & \\
\hline $\mathrm{Fe}\left(\mathrm{mg} \mathrm{L}^{-1}\right)$ & $<0,1$ & $<0,1$ & & & $<0,1$ & $<0,1$ & $<0,1$ \\
\hline $\mathrm{K}\left(\mathrm{mg} \mathrm{L}^{-1}\right)$ & 505 & 611 & 625 & & 38 & 123 & 251 \\
\hline $\mathrm{Li}\left(\mathrm{mg} \mathrm{L}^{-1}\right)$ & 0,466 & 0,536 & & & & & \\
\hline $\operatorname{Mn}\left(\mathrm{mg} \mathrm{L}^{-1}\right)$ & 0,058 & $<0,02$ & & & & & \\
\hline $\mathrm{Na}\left(\mathrm{mg} \mathrm{L}^{-1}\right)$ & 15.316 & 16.087 & & & 488 & 1.440 & 1.480 \\
\hline $\mathrm{P}\left(\mathrm{mg} \mathrm{L}^{-1}\right)$ & 0,384 & 0,556 & & & & & \\
\hline $\mathrm{V}\left(\mathrm{mg} \mathrm{L}^{-1}\right)$ & 0,142 & 1,204 & & & & & \\
\hline $\mathrm{Zn}\left(\mathrm{mg} \mathrm{L}^{-1}\right)$ & $<0,05$ & $<0,05$ & & & & & \\
\hline
\end{tabular}


Observa-se que outros estudos de caracterização de rejeito proveniente de dessalinizadores da água do mar, citados por Rabah (2017) e Silva (2019), apresentaram características semelhantes aos resultados de caracterização da amostra utilizada neste estudo, apresentados na Tabela 2. Os rejeitos do dessalinizador da ETA Boldró apresentam pH alcalino, sendo em função principalmente dos altos teores de cálcio e magnésio observados, de forma geral, os parâmetros dureza total, sulfato e cloretos do rejeito apresentam concentração bastante elevada, comparativamente da ordem de dez vezes mais concentrados que os observados por Mota et al (2005) que utilizou rejeito oriundo da dessalinização de águas subterrâneas salobras no Ceará, e acima dos padrões previstos no CONAMA 430/11 e 357/05. A concentração de cloretos no rejeito em estudo é da ordem de $3,8-4 \times 10^{4} \mathrm{mgL}^{-1}$.

Esta característica do rejeito da dessalinização da água do mar, de elevada dureza provavelmente será um limitante na geração de cloro, tendo em vista que, como apresentado por Kraft et al., Part I, 1999 e Kraft et al., Part II, 1999, haverá a formação de um filme fino de calcário na superfície do catodo, constituído essencialmente de $\mathrm{CaCO}_{3}$ e de $\mathrm{Mg}(\mathrm{OH})_{2}$ como resultado do aumento do $\mathrm{pH}$ na superfície de reação desse eletrodo. Sendo assim, na condução do planejamento fatorial foi considerado como variável o efeito de diluição da amostra.

\subsection{Planejamento Fatorial}

Inicialmente foi feita a análise de variância para os dados obtidos no experimento, para verificação da validade das suposições obtidas.

Gráfico 1: Gráfico da probabilidade normal dos resíduos com 60 minutos.

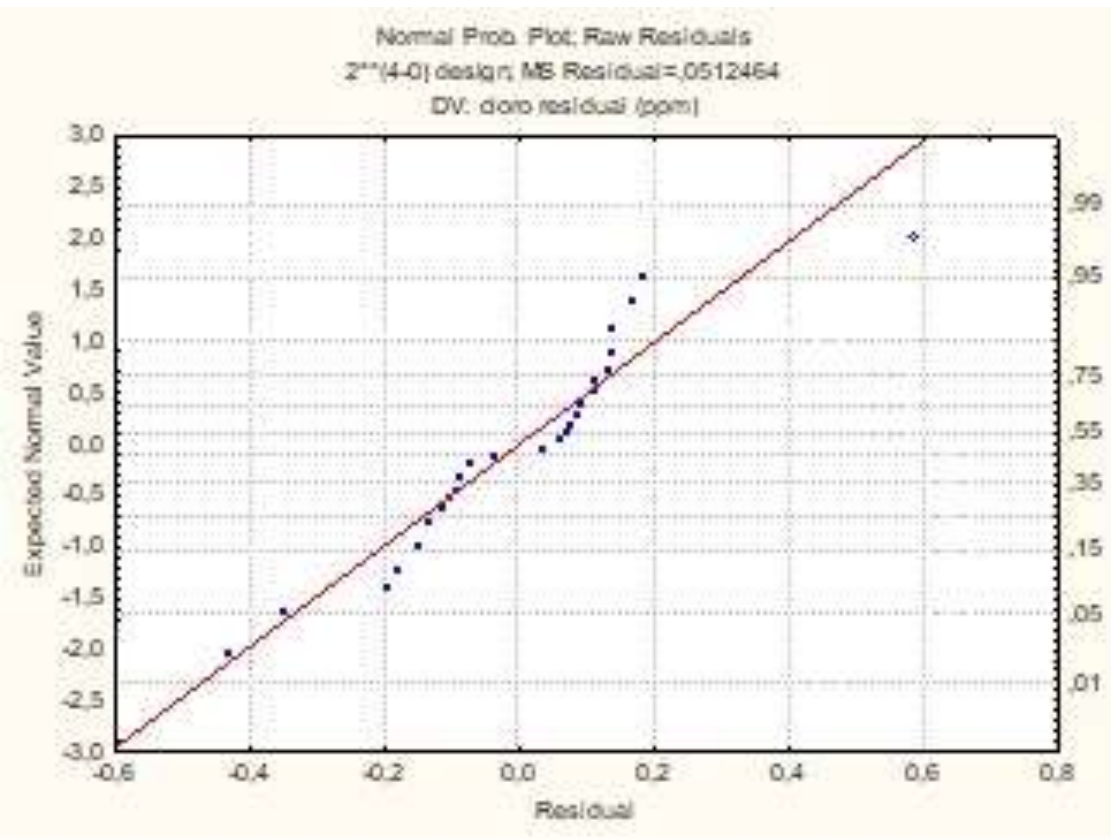

Fonte: Autores (2021).

Observa-se que os pontos experimentais estão próximos a linha contínua, corroborando o afirmado por Calado (2003) que quanto mais próximo os pontos experimentais estiverem da linha contínua, mais será válida a suposição de normalidade dos resíduos. Com relação ao Gráfico 1, pode-se dizer que os resíduos seguem uma distribuição normal.

A Tabela 3 apresenta o resultado do planejamento fatorial com os valores médios obtidos a partir da duplicata. 
Tabela 3: Planejamento Fatorial $2^{4}$ em 60 minutos.

\begin{tabular}{|c|c|c|c|c|c|c|c|c|c|}
\hline \multirow{2}{*}{ Ensaios } & \multicolumn{4}{|c|}{ Códigos } & \multicolumn{4}{|c|}{ Níveis de variáveis } & \multirow{2}{*}{$\begin{array}{c}\text { Geração } \\
\text { média de } \\
\text { Cloro } \\
\left(\mathrm{mgL}^{-1}\right)\end{array}$} \\
\hline & Anodo & Catodo & Diluição & Distância & Anodo & Catodo & Diluição & Distância & \\
\hline 1 & -1 & -1 & -1 & -1 & aço & titânio & 1 & 10 & 0 \\
\hline 2 & +1 & -1 & -1 & -1 & titânio & titânio & 1 & 10 & 0,26 \\
\hline 3 & -1 & +1 & -1 & -1 & aço & aço & 1 & 10 & 0,08 \\
\hline 4 & +1 & +1 & -1 & -1 & titânio & aço & 1 & 10 & 0,43 \\
\hline 5 & -1 & -1 & +1 & -1 & aço & titânio & 250 & 10 & 0,09 \\
\hline 6 & +1 & -1 & +1 & -1 & titânio & titânio & 250 & 10 & 0 \\
\hline 7 & -1 & +1 & +1 & -1 & aço & aço & 250 & 10 & 0,14 \\
\hline 8 & +1 & +1 & +1 & -1 & titânio & aço & 250 & 10 & 0,18 \\
\hline 9 & -1 & -1 & -1 & +1 & aço & titânio & 1 & 20 & 0,31 \\
\hline 10 & +1 & -1 & -1 & +1 & titânio & titânio & 1 & 20 & 0,43 \\
\hline 11 & -1 & +1 & -1 & +1 & aço & aço & 1 & 20 & 0,12 \\
\hline 12 & +1 & +1 & -1 & +1 & titânio & aço & 1 & 20 & 0,34 \\
\hline 13 & -1 & -1 & +1 & +1 & aço & titânio & 250 & 20 & 0 \\
\hline 14 & +1 & -1 & +1 & +1 & titânio & titânio & 250 & 20 & 0,20 \\
\hline 15 & -1 & +1 & +1 & +1 & aço & aço & 250 & 20 & 0,01 \\
\hline 16 & +1 & +1 & +1 & +1 & titânio & aço & 250 & 20 & 0,83 \\
\hline
\end{tabular}

Fonte: Autores (2021).

Observou-se experimentalmente que a maior concentração de cloro gerada foi no ensaio 16, na condição de: anodo (titânio), catodo (titânio), distância (20 mm) e diluição 1:250. Observou-se experimentalmente que no ensaio 16, condição que apresentou maior concentração de cloro, a temperatura permaneceu em $25{ }^{\circ} \mathrm{C}$ ao longo do experimento e houve a turvação e formação de precipitado branco em pequena quantidade, como ilustrado na Figura 3. Nesta condição, segundo Abdul-Wahab e Al-Weshahi, (2009) que estudaram os problemas associados a águas residuais geradas a partir do processo de dessalinização, os resultados dos experimentos estavam produzindo hipoclorito de sódio, o hidrogênio também foi gerado no ânodo e sais de carbonatos e hidróxidos que se depositam nos eletrodos e na célula eletrolítica. Mota et al (2005) observou a formação de sais precipitados nas soluções oxidantes em todos os rejeitos testados, e em sua caracterização indicou a presença de sulfato de magnésio $\left(\mathrm{CaSO}_{4}\right)$, sulfato de cálcio $\left(\mathrm{CaSO}_{4}\right)$, cloreto de sódio $(\mathrm{NaCl})$, cloreto de magnésio $\left(\mathrm{MgCl}_{2}\right)$ e cloreto de cálcio $\left(\mathrm{CaCl}_{2}\right)$. 
Figura 3: Formação de precipitado após reação de eletrólise com anodo Titânio e catodo aço nas condições ótimas do experimento após 60 minutos.

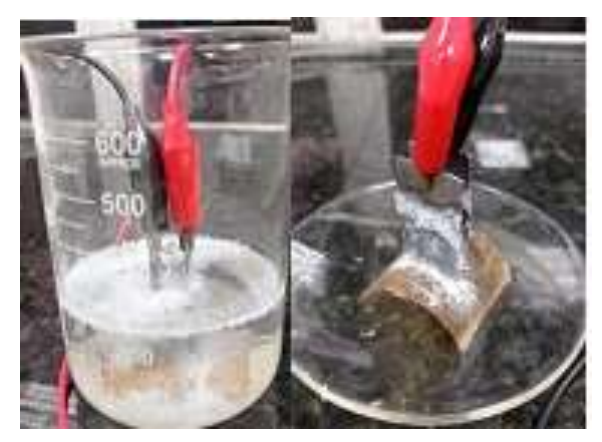

Fonte: Autores (2021).

Observou-se que nos demais ensaios a temperatura da amostra ao longo do experimento variava de $25^{\circ} \mathrm{C}$ a $60{ }^{\circ} \mathrm{C}$ e, nesta última condição se percebia a instabilidade no experimento. Sempre que ocorria a elevação da temperatura foi observado menor geração de cloro. Quanto maior a temperatura, menor a condutividade e, portanto, mais energia é necessária para gerar a mesma quantidade de cloro. Normalmente a temperatura da solução aumenta em função da corrente variando. Segundo Rabah (2017) o processo de eletrólise deve ser realizado em temperatura ambiente na qual uma concentração máxima de $\mathrm{NaOCl}$ pode ser gerada a $25^{\circ} \mathrm{C}$.

Dos eletrodos testados (aço inox e titânio), observou-se que o anodo quase sempre sofria oxidação, preferencialmente quando era de aço inox. O aço inox como anodo funcionava bem no início do experimento, mas era destruído pela corrente muito rápido, era perceptível que sofriam corrosão durante a operação (Figura 4).

Figura 4: Nível de oxidação do eletrodo de aço em comparação ao titânio ao final do experimento.

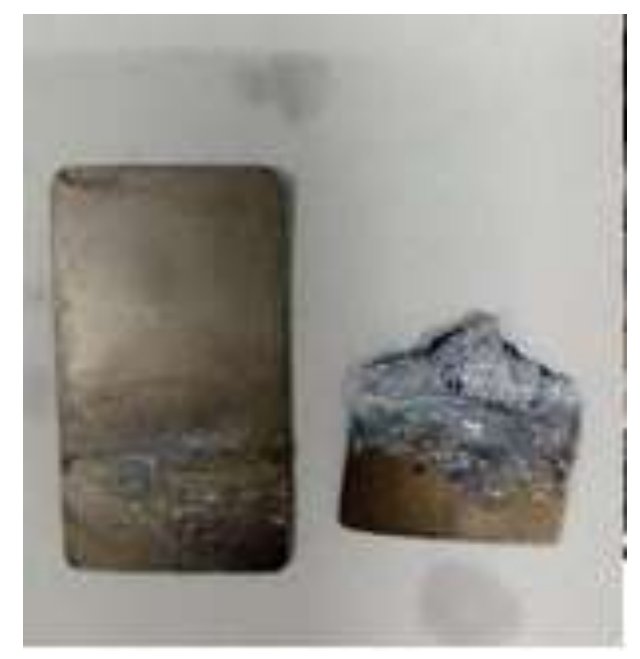

Fonte: Autores (2021).

Fazendo-se a análise e interpretação das variáveis estudadas através do Gráfico 2 de Pareto obtido no planejamento experimental: 
Gráfico 2: Pareto dos efeitos das variáveis e suas interações no fatorial $2^{4}$ com 60 minutos.

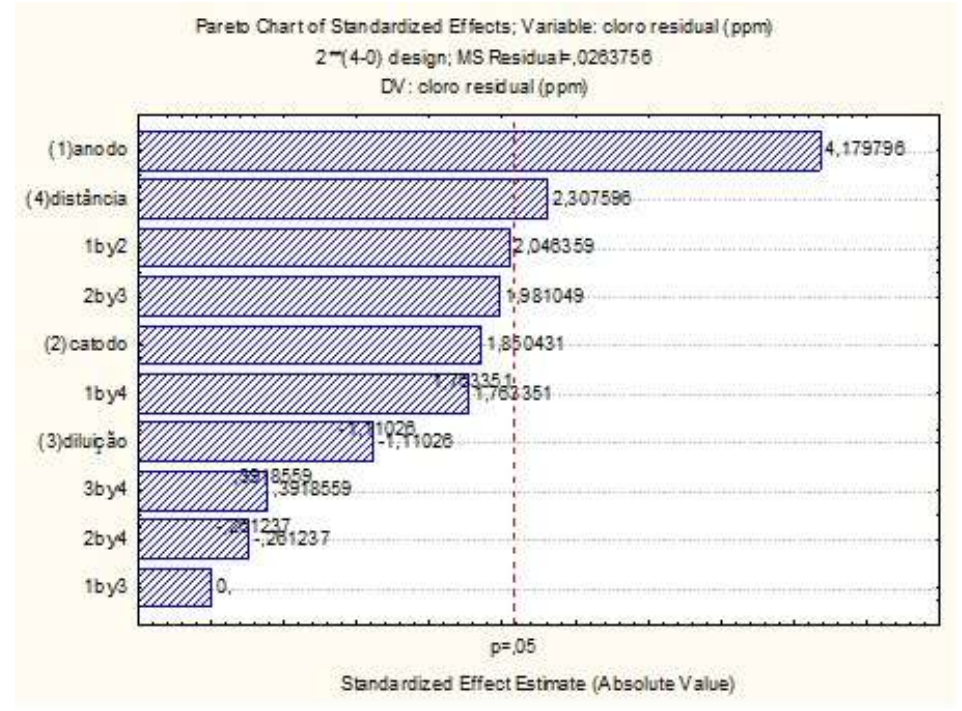

Fonte: Autores (2021).

A significância estatística dos efeitos principais e suas interações foram avaliadas por meio de análise de variância (ANOVA), mostrando que o anodo e a distância entre eletrodos afetaram significativamente a geração de solução oxidante (p $<0,05)$. São considerados significativos todos os valores situados à direita do ponto $\mathrm{p}(0,05)$. O Catodo e a diluição não foram significativos e a interação entre os fatores não tiveram efeitos significativos também.

Figura 5: Representação em 3D para a geração de solução oxidante em 60 minutos.

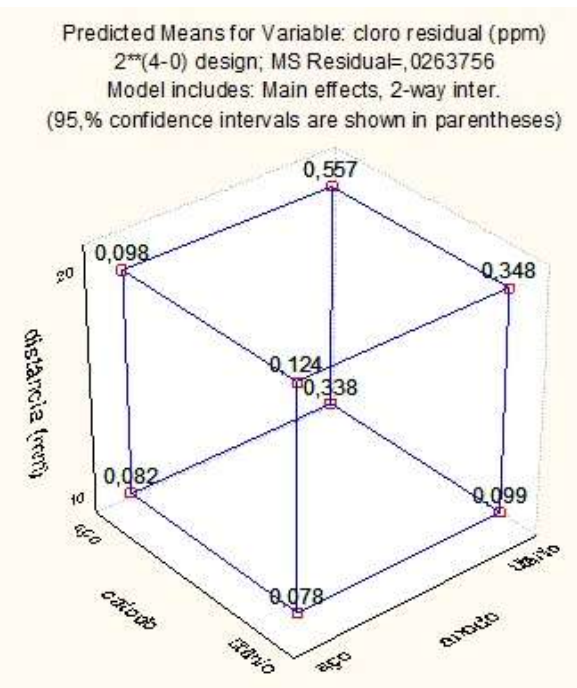

Fonte: Autores (2021).

Observa-se na representação geométrica da Figura 5 que as maiores concentrações de solução oxidante foram obtidas nas condições onde o anodo era titânio e a distância entre eletrodos de $20 \mathrm{~mm}$.

Em se aproximando os eletrodos, também observa-se maior remoção com anodo em titânio. Sendo o catodo em aço, a geração de cloro foi maior, independentemente das distâncias entre eletrodos. 
Uma análise da superfície de contorno para as interações dos efeitos principais mostram que:

Figura 6: Superfície de contorno para o efeito anodo e distância (mm).

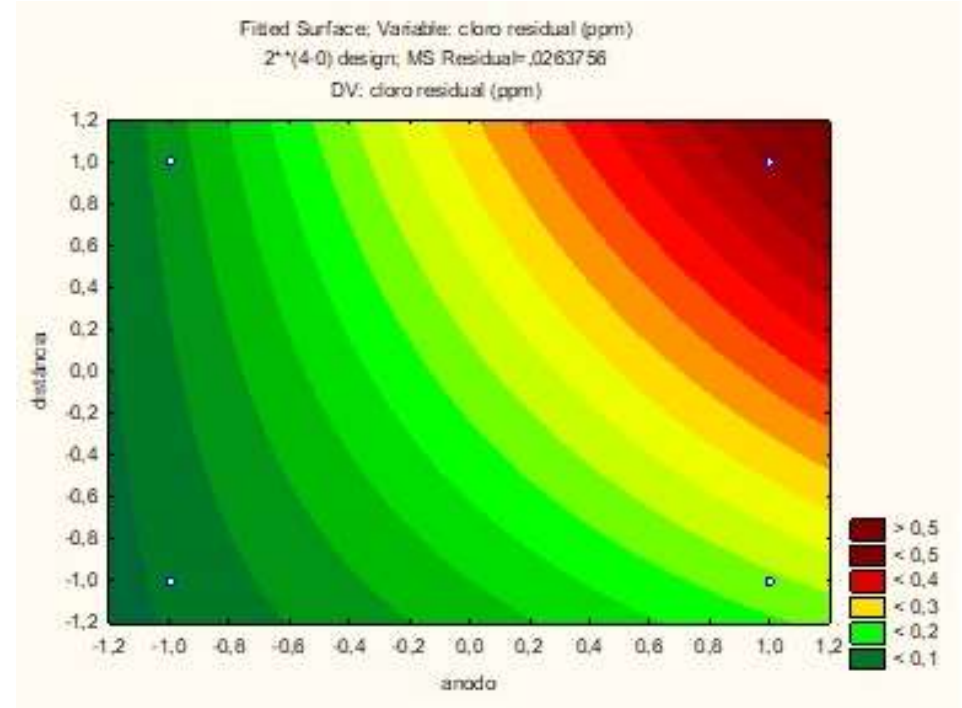

Fonte: Autores (2021).

Como observado na Figura 6 existe uma tendência na superfície para maior geração de cloro (intensidade vermelha) que se dá quando se caminha para o afastamento dos eletrodos e o anodo sendo de material titânio, reforçando o resultado apresentado em pareto.

Esta limitação da geração de cloro em função da proximidade dos eletrodos se deve a formação de camada passivados de sais na superfície do eletrodo. Observa-se que a geração de sais carbonatos e hidróxidos podem limitar a geração de solução oxidante, motivo pelo qual Rabah (2017) procedeu a remoção de dureza do rejeito com hidróxido de sódio antes de iniciar o experimento de eletrólise e Mota et al. (2005) fazia procedimento de limpeza dos eletrodos para remover as incrustações a cada batelada. O tempo de reação também pode limitar a geração de cloro, Abdul-Wahab e Al-Weshahi (2009) indicaram que a quantidade de hipoclorito gerado depende do tempo de reação e da tensão fornecida.

Existem poucos trabalhos que reportam a Geração de Solução oxidante a partir de rejeito, como é possível observar na Tabela 4 abaixo. Os trabalhos similares de caracterização de rejeito foram apresentados nos estudos de Mota et al. (2005) e Matos et al (2006) que utilizaram o rejeito de dessalinizadores de águas subterrâneas salobras do Ceará e de Rabah (2017) que utilizou rejeito de dessalinizadores do mar de Gaza, além deste projeto de pesquisa que utilizou rejeito de dessalinizadores da água do mar de Fernando de Noronha. 
Tabela 4: Estudos para a geração de solução oxidante a partir de rejeito de dessalizadores.

\begin{tabular}{|c|c|c|c|c|c|c|c|}
\hline Matriz & $\begin{array}{c}\text { Volume da } \\
\text { amostra }\end{array}$ & [Cloretos] & anodo & catodo & [Cloro] & $\begin{array}{l}\text { Tempo } \\
\text { reação }\end{array}$ & Referência \\
\hline $\begin{array}{l}\text { Rejeito de } \\
\text { dessalinizador } \\
\text { de água } \\
\text { subterrânia } \\
\text { (poços) }\end{array}$ & $25 \mathrm{~L}$ & $\begin{array}{c}1,7 \times 10^{3} \mathrm{mgL}^{-1} \\
5,5 \times 10^{3} \mathrm{mgL}^{-1} \mathrm{e} \\
10,2 \times 10^{3} \mathrm{mgL}^{-1}\end{array}$ & $\begin{array}{l}\text { Titânio/ } \\
\text { Rutênio }\end{array}$ & Titânio & $\begin{array}{l}0,10 \% \\
0,24 \% \\
\text { e } 0,27 \\
\% \mathrm{~m} / \mathrm{m}\end{array}$ & $480 \mathrm{~min}$ & $\begin{array}{l}\text { Mota et al. } \\
(2005) \text { e } \\
\text { Matos et al. } \\
(2006)) *\end{array}$ \\
\hline $\begin{array}{l}\text { Rejeito de } \\
\text { dessalinizador } \\
\text { de água do mar }\end{array}$ & $1,0 \mathrm{~L}$ & $3,7 \times 10^{4} \mathrm{mgL}^{-1}$ & $\begin{array}{l}\text { Cobre, Grafite, } \\
\text { aço e alumínio }\end{array}$ & $\begin{array}{c}\text { Cobre, } \\
\text { Grafite, aço } \\
\text { e alumínio }\end{array}$ & $1,9 \%$ & $120 \mathrm{~min}$ & $\begin{array}{c}\text { Rabah } \\
(2017) * *\end{array}$ \\
\hline $\begin{array}{l}\text { Rejeito de } \\
\text { dessalinizador } \\
\text { de água do mar }\end{array}$ & $0,25 \mathrm{~L}$ & $3,7 \times 10^{4} \mathrm{mgL}^{-1}$ & Titânio/aço & Titânio/aço & $\begin{array}{c}0,8 \\
\mathrm{mgL}^{-1}\end{array}$ & $60 \mathrm{~min}$ & $\begin{array}{c}\text { Este projeto } \\
* * *\end{array}$ \\
\hline
\end{tabular}

Fonte: Autores (2021)

* $30 \mathrm{~V}$, distância eletrodo não informada, sem remoção de dureza, área eletrodo $48 \mathrm{~cm}^{2}$

** $12 \mathrm{~V}$, distância eletrodos 5 a $40 \mathrm{~mm}$, com remoção da dureza prévia com $\mathrm{Na}(\mathrm{OH})$, área eletrodo: de 7 a $80 \mathrm{~cm}^{2}$.

*** $30 \mathrm{~V}$ distância eletrodos 10 e $20 \mathrm{~mm}$, sem remoção de dureza, área eletrodo $7,5 \mathrm{~cm}^{2}$

\section{Considerações Finais}

Com base nos resultados obtidos, nas condições estudadas, a partir da técnica de planejamento fatorial, pode-se inferir que:

- $\quad$ O planejamento experimental demonstrou que a condição mais favorável para geração de solução oxidante seria: a utilização de anodo de titânio, catodo de aço ou titânio, distância entre eletrodos de 20 mm e solução de rejeito diluída em 1:250, com tempo de reação de $60 \mathrm{~min}$, partindo de uma concentração inicial de cloretos de $38.000 \mathrm{mgL}^{-1}$;

- A análise estatística dos resultados obtidos dos ensaios de eletrólise do rejeito mostrou um nível de confiança de 95\% para todos os parâmetros estudados. Foram significativos o efeito anodo e distância entre eletrodos, não houve significância para os demais efeitos e suas interações;

- $\quad$ Este estudo apresenta alternativa do aproveitamento de rejeitos de dessalinizadores minimizando os impactos ambientais, principalmente no que se refere à salinização do solo e à contaminação das águas.

Os autores sugerem como trabalhos futuros, estudos cinéticos para avaliar a geração de solução oxidante, na intenção de obter maior concentração do oxidante, bem como, a investigação do potencial bactericida da solução oxidante gerada a partir do rejeito, na desinfecção de água para uso humano e de efluentes tratados e do aproveitamento do resíduo precipitado, gerado no processo de eletrólise na higienização de lodo de ETE.

\section{Agradecimentos}

Os autores agradecem a Rede Nordeste de Biotecnologia (RENORBIO) e Universidade Católica de Pernambuco (UNICAP) pelo apoio no desenvolvimento desta pesquisa e a Companhia Pernambucana de Saneamento (COMPESA) pela disponibilização da amostra e laboratório para as análises experimentais.

\section{Referências}

Abdul-wahab, S., \& al-weshahi, m. (2009). Brine Management: Substituting Chlorine with On-Site Produced Sodium Hypochlorite for Environmentally Improved Desalination Processes. Water Resour Manage, 23, 2437-2454. 
Ahmed, M., Shayya, W. H., Hoey, D., Mahendran, A., Morris, R., \& A1-Handaly, J. (2000). Use of evaporation ponds for brine disposal in desalination plants. Desalination, 130, 155-168. Amorim, M. C. C., de porto, E. R. Silva jnior, L. G. De A., liberal, G. DE S. Efeito de sais no solo provenientes de rejeitos da dessalinização por osmose inversa no semiárido pernambucano. In: congresso brasileiro de engenharia agricola, 26. 1997, Campina Grande. Anais. Campina Grande: SBEA; UFPB, 1997. 1 CD-ROM.

Alazaiza, M. Y., \& Mogheir, Y. K. (2013). Development of Safety Plan for Desalinated Water Use in Gaza Strip. Gaza.

Amorim, M. C. C. de., Porto, E. R., Silva JNior, L. G. de A., \& Liberal, G. de S.(1997) Efeito de sais no solo provenientes de rejeitos da dessalinização por osmose inversa no semiárido pernambucano. In: Congresso Brasileiro De Engenharia Agricola, 26. 1997, Campina Grande. Anais... Campina Grande: SBEA; UFPB, 1997. 1 CD-ROM.

Barros Neto, B., Scarmínio, I. S., \& Bruns, R. E. (2010) Planejamento e Otimização de Experimentos. 2. Ed. Campinas, Editora UNICAMP, 2010.

Calado, V. \& Montgomery, D. C. (2003) Planejamento de Experimentos usando o Statistica. E-papers Serviços Editoriais, 2003. El-Naas, M. H. (2011). Reject Brine Management. In M. Schorr (Ed.), Desalination,Trends and Technologies (pp. 237-252).

Eaton A. D., Rice, E. W., \& Baird, R. B. Standard Methods for the Examination of Water and Wastewater. 23rd edition. Washington, D.C.: American Public Health Association, 2017.

Kraft, A., Stadelmann, M., Blaschke, M., Kreysig, D., Sandt, B., Schroder, F., \& Rennau, J.(1999), Electrochemical water disinfection, Part I: Hypochlorite production from very dilute chloride solutions, Journal of Applied Electrochemistry, 29, 861-868.

Kraft, A., Blaschke, M., Kreysig, D., Sandt, B., Schroder, F., \& Rennau, J. (1999), Electrochemical water disinfection, Part II: Hypochlorite production from potable water, chlorine consumption and the problem of calcareous deposits, Journal of Applied Electrochemistry, 29, 895-902.

Matos, J. F., Mota, S., Avelino, F. F., Pádua, V. L., Braga, E. A. S., \& Malveir, J. Q. (2006) Solução oxidante gerada a partir da eletrólise de rejeitos de dessalinizadores de água. Revista Engenharia Sanitária e Ambiental, 11(2), 143-152. 2006.

Montenegro, A., Marinho, I., Silva, V. P., Andrade, A., Silva, J. G., Pereira, R., \& Albuquerque, K. S.(2001) Impacto do uso de água subterrânea salina em áreas agrícolas do programa Xingó. In: XIV Simpósio Brasileiro De Recursos Hídricos, 2001, Aracaju. Anais. Aracaju: ABRH, 2001. 1 CD-ROM.

Mota, S., Matos, J. F., \& Furtado, F. N.(2005) Aproveitamento de rejeitos salinos na irrigação e para geração e hipoclorito de sódio. In: Workshop Uso E Reúso De Águas De Qualidade Inferior, 2005, Campina Grande: UECG/UFPB. 2005, p, 453-471. CD-ROM.

Ministério do Meio Ambiente. Resolução $\mathrm{n}^{\circ} 430$ (2011). Conselho Nacional do Meio Ambiente (CONAMA), Brasília, DF, 13/05/2011. http://www2.mma.gov.br/port/conama/legiabre.cfm?codlegi=646.

Ministério do Meio Ambiente. Resolução $\mathrm{n}^{\circ} 357$ (2005). Conselho Nacional do Meio Ambiente (CONAMA), Brasília, DF 13/03/2005. http://www2.mma.gov.br/port/conama/legiabre.cfm?codlegi=459.

Peralta-Zamora, P., Morais, J. L., \& Nagata, N. (2005). Por que otimização multivariada? Engenharia Sanitária e Ambiental. 10(2), 106-110.

Porto, E. R., Amorim, M. C. C. de., Araújo, O. J., \& Silva Júnior, L. G. A. (1999); Aproveitamento dos rejeitos da dessalinização. In: Simpósio sobre Captação de Água de Chuva no Semi-Árido Brasileiro, 1,1997, Petrolina, PE. A captação de água de chuva: base para viabilização do semi-árido brasileiro Anais. Petrolina, PE: Embrapa Semi-Árido/IRPAA/IRCSA, 1999. p.51-57.

Porto, E. R. (2000) Potencialidades da erva-sal (Atriplex nummularia) irrigada com o rejeito da dessalinização de água salobra no Semi-Árido brasileiro como alternativa de reutilização. Congresso Interamericano De Engenharia Sanitária E Ambiental, XXVII. Porto Alegre. Anais... ABES, Ref. II-018.2000.

Porto, E. R., Amorim, M. C. C. De., \& Silva Júnior, L. G. de A. (2001) Uso do rejeito da dessalinização de água salobra para irrigação da erva-sal (Atriplex nummularia).Revista Brasileira de Engenharia Agrícola e Ambiental, 5(1), 111-114,2001.

Porto, E. R., Amorim, M. C. C. De., \& Araújo, O. J. (2020) Potencialidades da erva-sal (Atriplex nummularia) irrigada com o rejeito da dessalinização de água salobra no semi-árido brasileiro como alternativa de reutilização. http://www.cepis.ops-oms.org/bvsaidis/aresidua/x-003.pdf.

Rabah, F. (2017). Feasibility of Producing Sodium Hypochlorite for Water Disinfection Purpose Using Seawater Desalination Brine. thesis degree of Master of Civil Engineering-Infrastructure. October/2017. http://hdl.handle.net/20.500.12358/19345.

Rodrigues, M. I. \& Iemma, A. F. (2005) Planejamento de Experimentos e Otimização de Processos. Casa do Pão Editora, 2005.

Rosestolato, D., Bagatin, R., \& Ferro, S. (2015) Electrokinetic remediation of soils polluted by heavy metals (mercury in particular). Chemical Engineering Journal, 264, 16-23, 2015.

Silva, L. M., \& Baydum, V. P. A. (2019). Caracterização Do Rejeito do Processo de Dessalinização De Fernando De Noronha - PE e Possibilidades de Reúso. In: $30^{\circ}$ Cbesa Congresso Brasileiro De Engenharia Sanitária E Ambiental, 2019, Natal - RN. Anais. 